
Health Status, and Life Time Experiences of Violence Among Incarcerated Women

Barbara Joyce $^{1^{\star}}$, Kerry Peterson ${ }^{1}$, Valerie Sievers ${ }^{1}$, Vicki Brownrigg ${ }^{1}$ and Vanessa Hoener ${ }^{2}$

${ }^{1}$ Helen and Arthur E. Johnson Beth-El College of Nursing \& Health Sciences, University of Colorado Colorado Springs, 1420 Austin Bluffs Pkwy, Colorado Springs, CO 80918, USA

${ }^{2}$ Com Cor, Inc., 3808 N. Nevada, Colorado Springs, CO 80907

Abstract
The purpose of this descriptive correlational study was to describe parental acceptance and rejection
of incarcerated women and to determine whether a relationship exists between parental acceptance and
rejection, life time experience of abuse, and documented health status. Intake records of 100 incarcerated
women sentenced to community corrections and enrolled in a residential alchohol and drug treatment
program from June 2012 to June 2013 were used to examine relationship between the study variables.
The retrospective record audit of women incarcerated in a community correctional facility provided data
for correlational evaluation. The study concluded that parental acceptance and rejection appear to be
associated with life time experience of violence and current health status. Findings provide support for
life skill programs for incarcerated women transitioning back to the community.

\section{Publication History:}

Received: September 04, 2015

Accepted: October 04, 2015

Published: October 06, 2015

\section{Keywords:}

Incarcerated women, Parental acceptance and rejection, Physical abuse, sexual abuse, health status, community corrections

\section{Introduction}

Approximately seven out of every ten offenders serve all or part of their sentence in the community and each time a released inmate is kept from re-offending an innocent person is kept from becoming a victim [1]. Community corrections is a subfield of corrections that emphasizes rehabiltiation. Facilities support residential and nonresidential options. Offenders may be placed in community corrections as part of their sentence and fulfillment of their time. Community correctional agencies supervise over five million individuals per year which is the largest single sector of the correctional population [2]. The community corrections system is comprised of a number of diverse programs developed to provide alternatives to incarceration and facilitate re-entry into the community or following a term in prison [3]. A temporary period of highly structured and supportive living is provided to facilitate inmates to function independently upon release. Professionals monitor the progress and conduct of offenders during their sentence and assist offenders to reintegrate successfully back into society upon release.

Women are the fastest-growing segment of the prison population and the female prisoner population has more than doubled since 1990[4].There are over 200,000 women incarcerated in United States prisons, representing 8.8 percent of the total American prison population [5]. When also accounting for women on probation and parole, there are over one million women under the supervision of the criminal justice system [6]. Women's involvement in the criminal justice system often has negative impacts on the well-being of children. Approximately 7 in 10 women in the US correctional system have minor children [7] and the majority of these incarcerated mothers were the primary caretakers of their children before arrest [8]. Women leave prison with few tangible skills and face considerable obstacles once they re-enter the community. Women are more likely to recidivate when support services are lacking and quality of the relationship of the women with those who support them is crucial to their psychological adjustment and success [9].

There has been substantial attention given to women's experience of various types of abuse, such as intimate partner violence and child sexual abuse. Most of the research focuses on women in the community as opposed to incarcerated women, yet there is a growing body of literature documenting incarcerated women's extensive personal histories of violence and abuse [10-12]. Many incarcerated women have experienced some type of physical or sexual abuse at some point in their lives [13-15]. Fifty-seven percent of female prisoners report physical abuse before admission to state prison and 39\% report that they were sexually abused before admission [16]. More than onethird of imprisoned women report abuse by an intimate in the past and nearly one-quarter report prior abuse by a family member [17]. This overexposure to violence has widespread implications for both the mental and physical health of incarcerated women.

A history of physical abuse is associated with poor physical and mental health for female inmates [18-21]. Nearly three-quarters (73\%) of women in state prisons have symptoms of a current mental health problem [22]. Fifty-nine percent of women in prison have chronic and/or communicable medical problems[23]. Psychological violence is very difficult to define and has been understudied in this population perhaps due to problems in definition. As applied to children, psychological abuse includes acts that have an adverse effect on the psychological and emotional health and development of a child and includes the lack of an emotional and supportive environment [24].

\section{Theoretical Framework}

Parental acceptance-rejection theory (PART), is a theory of socialization that attempts to explain and predict major antecedents, correlates, and consequences of parental acceptance and rejection. [25]. Parental acceptance refers to the physical and verbal warmth, affection and love parents give to their children. Parental rejection is defined as the absence or significant withdrawal of warmth, "Corresponding Author: Dr. Barbara Joyce, Helen and Arthur E. Johnson Beth-El College of Nursing \& Health Sciences, University of Colorado Colorado Springs, 1420 Austin Bluffs Pkwy, Colorado Springs, CO 80918, USA; E-mail: bjoyce@uccs.edu

Citation: Joyce B, Peterson K, Sievers V, Brownrigg V, Hoener V (2015) Relationship Between Parental Acceptance and Rejection, Documented Health Status, and Life Time Experiences of Violence Among Incarcerated Women. Int $J$ Nurs Clin Pract 2: 147. doi: http://dx.doi.org/10.15344/2394-4978/2015/147

Copyright: (c) 2015 Joyce et al. This is an open-access article distributed under the terms of the Creative Commons Attribution License, which permits unrestricted use, distribution, and reproduction in any medium, provided the original author and source are credited. 
Citation: Joyce B, Peterson K, Sievers V, Brownrigg V, Hoener V (2015) Relationship Between Parental Acceptance and Rejection, Documented Health Status, and Life Time Experiences of Violence Among Incarcerated Women. Int J Nurs Clin Pract 2: 147. doi: http://dx.doi.org/10.15344/2394-4978/2015/147

Page 2 of 7

affection or love by parents toward children and takes three major forms: 1) hostility and aggression, 2) indifference and neglect, and 3) undifferentiated rejection (the feeling of being unloved, unwanted or rejected without having any positive indicators present). A conceptual model for the theory predicts a link between parental rejection and the development of a set of personality characteristics with consideration to variables of the natural environment, maintenance systems and parental behavior [26].

Social and cultural expectations of norms of family interactions may provide depth to understanding of the influence of psychological violence. Perceptions of parental acceptance and rejection have not been assessed in incarcerated women and the relationship to violence and health of incarcerated women may provide depth in understanding to facilitate future program planning. Familial influence (acceptance and rejection) and use of famialiar methods of interaction and coping with intimate partners may have an influence on life change required for successful community reintegration after prison.

\section{Background}

Parental rejection is not a specific set of actions by parents but a belief held by an individual and can be studied as percieved or subjectively experienced by the individual $[27,28]$. Adults who perceive themselves to be rejected appear to be disposed toward behavior problems and conduct disorders, to be depressed or have depressed affect, and to become involved in drug and alchohol abuse [29]. Parental acceptance and rejection is postulated to have unparalleled influence in shaping personality over time. An adult's sense of emotional security and wellbeing tends to be dependent on the perceived quality of relationships with attachment figures; thus acceptance or rejection by an intimate partner is also postulated to have influence on an adult's personality and psychological adjustment. The study of parental acceptancerejection has a history going back to the 1890's, and since the 1930's a more continuous body of empirical research can be documented with currently over 1,700 studies available on the topic[30]. There has been very little empirical research examining parental acceptance and rejection among correctional populations. Elkon[31] conducted a retrospective study examining developmental correlates of antisocial behavior among 105 incarcerated women. Specifically, the study examined the nature of recalled parental rejection and control, recalled adolescent misconduct, and adult antisocial behavior. There were significant relationships between recalled caregiver rejection/ control and recalled adolescent misconduct as well as adult antisocial behavior. Joo [32] conducted a study examining the relationship between past experiences of child abuse and current parenting practices among 199 incarcerated women at a maximum-security state prison. The results indicated there were moderate correlations between past experiences of abuse and current parenting practices. The incarcerated women's perceptions of poor relationships with their own mothers or perceptions of having been neglected was associated with emotional abuse practices towards their own children, above and beyond past abuse experiences.

Esquivel [33] examined the psychological adjustment and parental relations (including perception of acceptance and/or rejection) of adolescent sex offenders and their non-offending siblings. A total of 60 adolescent sex offenders residing in two different residential facilities participated in the study along with 34 siblings. The findings demonstrated that adolescent sex offenders were significantly more likely to experience greater maternal rejection than their siblings, but not significantly greater paternal rejection. In addition, greater perceived rejection by parents was correlated with greater psychological maladjustment. Finally, Rafail and Haque [34]) conducted a study in Pakistan with 100 male juvenile criminal and non-criminal adolescents. The results of the study found that juvenile delinquency was positively associated with the total perceived acceptance-rejection scores. The criminal adolescents perceived both parents to be significantly more aggressive, neglecting, and rejecting compared to the non-criminal adolescents.

With the development of community correctional programs to provide education and training to facilitate life change and reduce recidivism there is increased interest in factors that impact adult behavior, behavior as a parent and intervening developmental experiences (violence) that may influence recidivism. Early childhood experiences and perceptions of adversity and maltreatment influence pyschological and physiological responses [35-37]. Sustained experiences not buffered by supportive relationships or in the absence of protective relationships create prolonged activation of the stress response and result in long term behavioral (depression, dysfunctional coping activities) and health consequences (elevated blood pressure,glucose, cortisol, inflammation). The link between the biology of adversity and health is the interest of this study and the study provides information that can influence the design of life skills programs related to strengthening relationships that promote health.

The emotional need for postive response from significant others and attachment figures is a powerful motivator, and children or adults who do not get this need satisfied adequately are predisposed to respond emotionally and behaviorly in specific ways, which have been identified as defensive independence and associated personality outcomes such as hostility and aggression [38]. The impact of incarceration on families has been conceptualized as a form of family crises, loss and demoralization and victimization of children $[39,40]$. Each year in the United States over 3.4 million children are reported to protective services for child maltreatment, and violence has been described as a national epidemic [41]. It is possible that many more children may be rejected, abused, neglected and maltreated than are actually reported. Emotional maltreatment or rejection may not leave visible marks but can be more damaging and lead to serious injury or impairment such as attempted suicide or drug overdose. There is robust evidence of the relationship between child abuse and adult violence and these factors in lives of incarcerated women increase probability of continued violence after release [42]. Life experiences of women that may influence incarceration and/or have potential for causing decreased success after release or recidivism was the specific interest of this investigation.

\section{Purpose}

The purpose of this study was to describe parental acceptance/ rejection (PAR) of incarcerated women and to determine if a relationship exits between PAR, life time experience of violence, and documented health status. This study of incarcerated women posed three research questions: 1) What is the frequency of PAR among incarerated women?, 2) What is the relationship of PAR to history of physical/sexual abuse? and, 3) What is the relationship of PAR to documented health status?

\section{Methods}

The setting for this investigation was a community correctional facility with a women's unit transitioning inmates coming out of the Department Corrections and back to society prior to release. 
Citation: Joyce B, Peterson K, Sievers V, Brownrigg V, Hoener V (2015) Relationship Between Parental Acceptance and Rejection, Documented Health Status, and Life Time Experiences of Violence Among Incarcerated Women. Int J Nurs Clin Pract 2: 147. doi: http://dx.doi.org/10.15344/2394-4978/2015/147

All women were enrolled in a residential alcohol and drug treatment program. A retrospective chart audit of inmate records provided a database for a descriptive correlational study of parental acceptance and rejection, history of child/adult physical and sexual abuse, and documented health status of incarcreated women. Upon admission to the community correctional facility the individual signs an informed consent for evaluation and treatment. The inmate participates in three types of assessments and evaluations. Initially the inmate is assigned to a case manager for a Standardized Offender Assessment (SOA) which includes measures of alcohol and drug abuse problems, a profile for criminogenic needs and an initial brief medical assessment [43]. Based on this initial screening treatment and referrals are planned and the individual is then recommended for at least one of the intensive inpatient treatment programs. Inmates are then asked to complete an Adult Information Form as part of Level One testing. The Adult Information Form includes demographic data, personal and social history, educational experience, work history, legal/criminal status, medical status and history, drug and alcohol history and behavioral assessment, Parental Acceptance/Rejection Questionnaire and the Sexual \& Physical Abuse History Questionnaire. Inmates are provided the opportunity to refuse participation in any class activities or assessments. All assessments are documented in the individual client chart. Refusal to participate in an assessment and rationale is also noted in the record.

\section{Instruments}

Standard Offender Assessment (SOA)Tool: The Standard Offender Assessment Tool is used for initial intake, immediate treatment and referral needs [44]. The tool asks the inmate to list their medical conditions. Number of medical conditions listed was used as a variable for analysis and to determine health status.

Adult Information Form: The Adult Information Form asks the inmate to provide personal data which includes age, ethnicity, maritial status, educational expeience, personal and social history, violence and abuse history, work history, legal/criminal history, medical history, health status, drug and alcohol history and behavioral assessment. Data from this intake was used to describe the aggregate sample population and identify specific variables of the study for investigation; health status and life time experience of violence. For the purposes of this study, health status data was retrieved from responses to two questions related to identification of medical problems interfering with life and identification and use of current prescription medications. Inmates responded to two specific questions: Do you have medical problems interfering with your life? (Yes or No) and, Are you currently using perscription medications? (Yes or No). Sexual and physical abuse history was used to define life time experience of violence. Inmates respond to three questions: Sexual Abuse as a child and as an adult (Yes or No) and physical abuse as a child (Yes or No).

Parental Acceptance and Rejection Questionnaire: The Parental Acceptance-Rejection Questionnaire (PARQ) is a self-report instrument designed to measure individuals' perceptions of parental acceptance-rejection [45]. Parental acceptance-rejection is a bipolar dimension, with acceptance defining one end of the continuum and parental rejection defining the other. Parental rejection is expressed in any combination of four forms: coldness/lack of affection, hostility/ aggression, indifference/neglect, and in undifferentiated rejection. Undifferentiated rejection refers to conditions where individuals perceive their parent to be rejecting, but where the expression of rejection is not clearly unaffectionate, aggressive or neglecting. The
Adult PARQ assesses perception of their mother's or father's treatment of them when they were about seven through twelve years old. The PARQ Short Form was used for the assessment of perceptions of mother and father treatment. The Short Form consists of 24 questions that ask for a Likert type response indicating "almost always true", "sometimes true", "rarely true", "almost never true". Scores over 60 indicate rejection. PARSCORE IV, a Windows-based software program, was used for scoring the self-report questionnaires. The program automatically does all required scoring and reverse scoring; computing scores for scales with missing data, computing totals scale scores, and computing total test scores. A data file was created for export to Statistical Package for Social Sciences (SPSS) Version 21 [46]. Cronbach's coefficient aplha has been used to measure the internal consistency of the items on the Adult PARQ mother and father versions. The PARQ reliability coefficients for the mother and father versions range from .86 to .95 with a median reliability of .91 $[47,48,49]$.

\section{Procedures and Sample}

The study was conducted following full review and approval from the Institutional Review Board of the University of Colorado at Colorado Springs. Inmates sign a consent for evaluation and treatment, a consent for participation in research and a consent for follow-up contact after discharge from the facility. The population for the study was women incarcerated in communty corrections facility who were enrolled in a residential drug and alcohol treatment program transitioning back into the community post prision or jail sentence. All women were sentenced for non-violent crimes of forgery, burglury and/or driving under the influence.

The investigators first screened individual charts to determine if consent for Particicipation in Research had been signed to protect individual human rights. Records in which no consent for participation in research existed were elminated from the study. Nine records were eliminated due to no signed consent and sixteen records were eliminated due to lack of the individual participating in the assessments. The final population sample was seventy-five women participating in transistion programs between June 2012 and June 2013.

An audit was conducted of the records of incarcerated women enrolled in an residential alcohol and drug treatment program. A audit tool was developed and used to facilitate data collection. A retrospective chart audit of the Adult Information Form, the Medical History and Health Status, the Sexual and Physical Abuse History and the Parental Acceptance and Rejection Questionnaire was completed. Each record was assigned a number in order to deindentify health information during documentation of the chart audit data. No names or identity data that could identifiy an individual was used on the record audit tool used for data collection. Only the Principal Investigator and Project Director had access to the record for purposes of this audit. Record audit information (participant number and assessment scores) were transposed onto an excel spreadsheet by the investigators for the purposes of data analysis.

Analyses were performed using the Statistical Package for Social Sciences Version 21 [50]. Descriptive analyses were conducted to describe the demographics. A series of Pearson product moment correlation tests was used to measure the degree of associations among the variables: parental rejection, violence, and documented health status. Information derived from the analyses was used to address the research questions. 
Citation: Joyce B, Peterson K, Sievers V, Brownrigg V, Hoener V (2015) Relationship Between Parental Acceptance and Rejection, Documented Health Status, and Life Time Experiences of Violence Among Incarcerated Women. Int J Nurs Clin Pract 2: 147. doi: http://dx.doi.org/10.15344/2394-4978/2015/147

\section{Results}

\section{Characteristics of the sample}

Table 1 shows the demographic characteristics of the study participants. Descriptive analyses were conducted to describe the demographics of the 75 women whose records were audited in the community corrections program. The sample included $1.3 \%$ who were 19 years old or younger, $28 \%$ were $20-29$ years old, $41.3 \%$ were $30-39$ years old, $22.7 \%$ were $40-49$ years old and $6.7 \%$ were $50-59$ years old. The majority of the sample (61\%) were Caucasian, $25 \%$ were Hispanic and $4 \%$ African American. Asian and Native American individuals each represented $1 \%$ of the sample. Six percent identified "other" or "combination" as their ethnicity. Thirty five percent had completed high school or GED $(\mathrm{N}=26)$ and $28 \%$ had less than a high school

\begin{tabular}{|l|l|l|}
\hline Characteristic & $\mathrm{n}$ & $\%$ \\
\hline Age at time of survey (years) & & \\
\hline$\leq 19$ & 1 & 1.3 \\
\hline $20-29$ & 21 & 28 \\
\hline $30-39$ & 31 & 41.3 \\
\hline $40-49$ & 17 & 22.7 \\
\hline $50-59$ & 5 & 6.7 \\
\hline Ethnicity & & \\
\hline Caucasian & 46 & 61.3 \\
\hline Hispanic & 19 & 25.3 \\
\hline African American & 3 & 4 \\
\hline Asian & 1 & 1.3 \\
\hline Native American & 1 & 1.3 \\
\hline Other & 2 & 2.7 \\
\hline Combination & 3 & 4 \\
\hline Education & & \\
\hline High School or GED & 26 & 34.7 \\
\hline Less than High School & 21 & 28 \\
\hline High School +Business Classes & 7 & 9.3 \\
\hline $1-4$ years of College without graduation & 14 & 18.7 \\
\hline College graduation & 2 & 2.7 \\
\hline Missing data & 2 & 2.7 \\
\hline Parental Status & & \\
\hline Yes & 51 & 68 \\
\hline No & 20 & 27.7 \\
\hline Missing Data & 4 & 5.3 \\
\hline & & \\
\hline & & \\
\hline & & \\
\hline & & \\
\hline & & \\
\hline & & \\
\hline
\end{tabular}

Table 1: Demographic Characteristics of Participants $(\mathrm{N}=75)$.

education $(\mathrm{N}=21)$. Nine percent reported completion of high school with some business classess $(\mathrm{N}=7)$. Nineteen percent $(\mathrm{N}=14)$ reported between one and four years of college without graduation and three percent reported college graduation $(\mathrm{N}=2)$. Missing data accounted for four percent $(\mathrm{N}=3)$. Sixty eight percent $(\mathrm{N}=51)$ identified themselves as being a parent.

\section{Results for research question 1}

Sixty-one percent $(\mathrm{N}=46)$ described perceptions of paternal acceptance and seventy-three percent $(\mathrm{N}=55)$ described perceptions of maternal acceptance. Therefore, twenty-four percent $(\mathrm{N}=18)$ described paternal rejection and twenty-five percent $(\mathrm{N}=19)$ described maternal rejection. Missing data accounted for fifteen percent of paternal acceptance/rejection responses $(\mathrm{N}=11)$ and one percent of maternal acceptance/rejection responses $(\mathrm{N}=1)$.

\section{Results for research question 2}

Forty-one percent $(\mathrm{N}=31)$ reported sexual abuse as a child and forty-two percent $(\mathrm{N}=32)$ reported physical abuse as a child. As shown in Table 2, correlation data indicate ndicate the maternal PARQ score (ie., acceptance/rejection) was positively associated with physical abuse $\mathrm{r}(60)=.282, \mathrm{p}<.05$. This indicates that as the maternal PARQ score increased, the reported physical abuse increased. An even greater positive relationship was found between the paternal PARQ score and physical abuse, $r(51)=.409, \mathrm{p}<.01$ at the .05 level of significance and a significant relationship (.409) of father acceptance/rejection with physical abuse at the .01 level of significance. A significant positive relationship (.303) between paternal perceived rejection and sexual abuse was demonstrated at the .05 level of significance. A positive relationship was found between the paternal PARQ score and sexual abuse $\mathrm{r}(56)=.303, \mathrm{p}<.05$, however the relationship between maternal PARQ score and sexual abuse was not statistically significant.

\begin{tabular}{|c|c|c|c|}
\hline Measure & 1 & 2 & 3 \\
\hline 1. Father's acceptance and rejection & --- & & \\
\hline 2. Mother's acceptance and rejection & $.249^{*}$ & --- & \\
\hline 3. Physical Abuse & $.409^{* *}$ & $.282^{\star}$ & --- \\
\hline 4. Sexual Abuse & $.303^{*}$ & .237 & $.529^{* *}$ \\
\hline \multicolumn{4}{|c|}{$\begin{array}{l}\text { Table 2: Intercorrelations for Parental Acceptance or Rejection and } \\
\text { Abuse. } \\
{ }^{\star} \text { Correlation is significant at the } 0.05 \text { level ( } 2 \text {-tailed) } \\
{ }^{*} \text { Correlation is significant at the } 0.01 \text { level ( } 2 \text { tailed) }\end{array}$} \\
\hline
\end{tabular}

Results for research question 3

On intake the inmate was asked to complete a medical status report which asked the question: Do you have a medical problem? The inmate was asked to respond with "yes" or "no". This initial screen provided information that was used by correctional staff for referral to health care resources. Approximately 35\% $(\mathrm{N}=26)$ reported they had a medical problem on intake. In additon, on the social history the inmate was asked if they had a chronic medical condition interfering with their life. Intake personnel asked the question: Do you have a personal health history of any of the following conditions or diseases? Fourteen conditions were listed and the inmate was asked to check all that applied. The inmate also could check "none of the above" or "don't know, not sure".

Eighty-four percent $(\mathrm{N}=63)$ reported at least one chronic health problem. Approximately $57 \%(\mathrm{~N}=43)$ indicated they had one medical problem, $12 \%(\mathrm{~N}=9)$ identified two medical problems, and $14.6 \%$ $(\mathrm{N}=11)$ identified three or more chronic health problems. Sixteen percent $(\mathrm{N}=12)$ identified "none" even though they were enrolled in a alcohol/drug treatment program. Medical intake also requested informaton regarding their use of prescription medications by asking the question: Are you currently taking prescription medications? Approximately, 45\% ( $\mathrm{N}=34)$ responded that they were taking medications for their medical problems.

Table 3 shows the results of correlational analysis of Parental Acceptance/Rejection (i.e. PARQ), with identification of medical 
Citation: Joyce B, Peterson K, Sievers V, Brownrigg V, Hoener V (2015) Relationship Between Parental Acceptance and Rejection, Documented Health Status, and Life Time Experiences of Violence Among Incarcerated Women. Int J Nurs Clin Pract 2: 147. doi: http://dx.doi.org/10.15344/2394-4978/2015/147

problems and chronic medical problems affecting life. There was a significant positive relationship between the identification of medical problems and chronic medical problems interfering in life, $r(63)=$, $\mathrm{p}<.05$. There was also a positive relationship between the mother's PARQ score and the identification of medical problems, $r(62)=.303$, $\mathrm{p}<.05$. This means that as the maternal PARQ score increased, reports of medical problems increased. A significant relationship between the paternal PARQ scores and identification of medical problems not found. Similarly, a significant relationship between both the maternal and paternal PARQ scores and identification of specific chronic medical problems that interfere with life was not found. Table 3 also depicts the correlations between the three items of chronic medical problems interfering with life, medical problems and current use of prescription medications. There was a significant positive relationship between chronic medical problems interfering in life and currently taking prescription medication $\mathrm{r}(67)=.324, \mathrm{p}<.01$. This means that as the number of reported chronic medical problems increased, there was also increased reports of taking prescription medication.

\begin{tabular}{|l|l|l|l|l|}
\hline Measure & 1 & 2 & 3 & 4 \\
\hline 1. Father's acceptance and rejection & --- & & & \\
\hline 2. Mother's acceptance and rejection & $.249^{*}$ & --- & & \\
\hline 3. Medical Problems & -.062 & $.303^{*}$ & --- & \\
\hline $\begin{array}{l}\text { 4. Chronic Medical Problems } \\
\text { Interfering with Life }\end{array}$ & -.068 & .053 & $.269^{*}$ & --- \\
\hline 5. Current use of Prescriptions & $.314^{*}$ & .017 & .035 & $.324^{* *}$ \\
\hline
\end{tabular}

Table 3: Intercorrelations for Parental Acceptance or Rejection and Medical Problems.

${ }^{\star}$ Correlation is significant at the 0.05 level (2-tailed).

${ }^{* *}$ Correlation is significant at the 0.01 level ( 2 tailed).

On intake the inmate was asked to complete a medical status report which asked the question: Do you have a medical problem? The inmate was asked to respond with "yes" or "no". This initial screen provided information that was used by correctional staff for referral to health care resources. Approximately 35\% $(\mathrm{N}=26)$ reported they had a medical problem on intake. In additon, on the social history the inmate was asked if they had a chronic medical condition interfering with their life. Intake personnel asked the question: Do you have a personal health history of any of the following conditions or diseases? Fourteen conditions were listed and the inmate was asked to check all that applied. The inmate also could check "none of the above" or "don't know, not sure".

Eighty-four percent $(\mathrm{N}=63)$ reported at least one chronic health problem. Approximately $57 \%(\mathrm{~N}=43)$ indicated they had one medical problem, $12 \%(\mathrm{~N}=9)$ identified two medical problems, and $14.6 \%$ $(\mathrm{N}=11)$ identified three or more chronic health problems. Sixteen percent $(\mathrm{N}=12)$ identified "none" even though they were enrolled in a alcohol/drug treatment program. Medical intake also requested informaton regarding their use of prescription medications by asking the question: Are you currently taking prescription medications? Approximately, 45\% ( $\mathrm{N}=34)$ responded that they were taking medications for their medical problems.

Table 3 shows the results of correlational analysis of Parental Acceptance/Rejection with identification of medical problems and chronic medical problems affecting life. There was a significant relationship (.269) between the identification of medical problems and chronic medical problems interfering in life at the .05 level of significance. There was also a significant relationship (.303) between the mother's acceptance and rejection and the identification of medical problems at the .05 level of significance. Table 3 also depicts the correlations between the three items of chronic medical problems interfering with life, medical problems and current use of prescription medications. There was a positive relationsip between chronic medical problems interfering in life and currently taking prescription medication (.324) at the .01 level of significance.

\section{Discussion}

This study provides valuable insight for future program development related to life skills, stress, coping, parental role behaviors, violence prevention strategies and related identification of need for health care for incarcerated women who plan to return to the community with their children. The outcomes of this study described a population of women offenders who predominately described maternal acceptance (73\%) and paternal acceptance (61\%) while reporting phyical abuse (42\%) and sexual abuse as a child (41\%). This data suggests the social acceptance of violence in family situations as a norm. Social, cultural and famialial interaction norms related to violence may have influence and impact on individual offender coping and recidivism. Increased content in life skills programming for women offenders related to the topic of violence (prevention, early types of violence, the cycle of violence and skill development to facilate behavior change may be warranted for prevention of violence after release. There was a significant relationship of physical abuse (.409@.01 level of significance) and sexual abuse (.303 @.05 level of significance) with paternal parental rejection. This strong correlation indicates the need for further investigation with male offenders, life skill parenting classes for men and suggests need for fatherhood training with male offenders. Programs that introduce and provide simulation for acceptable parenting behaviors may positively influence individual coping skills and community domestic violence incidence rates. This data suggests the need for caring for children of incarcerated parents and of those caring for the children of incarcerated parents. Early intervention programs related to acceptance and rejection behavior may have postive impact on family situations that may result in incarceration.

Only $35 \%$ of the sample initially reported they had a medical problem on intake and $16 \%$ indicated no medical problem on the medical history assessment, although all individuals were enrolled in an alcohol and drug treatment intervention program. The lack of understanding of alcoholism and drug use as a medical problem which influences health and behavior may influence intervention outcomes. Attention to the relationship between behavior and health through increased health education and wellness interventions may influence positive community transitions and postive health. Preventive health care in community corrections is indicated for community transitioning and prevention of recidivism. In addition, the significant relationship (.269) between the two questions regarding medical health; one on the initial intake and again on the Adult Information Form provides evidence of the reliability of the reported health information.

The significant relationship (.303) between the mother's acceptance and rejection and the identification of medical problems may indicate the important role of the mother in health awareness and the influence of family lifestyle norms (e.g. nutrition, exercise) that impact health. In addition, the correlation between chronic medical conditions and use of perscription medication (.324) may support the warmth dimension as a foundation for positive health behavior. 
Citation: Joyce B, Peterson K, Sievers V, Brownrigg V, Hoener V (2015) Relationship Between Parental Acceptance and Rejection, Documented Health Status, and Life Time Experiences of Violence Among Incarcerated Women. Int J Nurs Clin Pract 2: 147. doi: http://dx.doi.org/10.15344/2394-4978/2015/147

Page 6 of 7

\section{Implications for Further Research}

The correctional system routinely collects data and uses the information to develop individual treatment plans. Use of existing data to better understand the research variable in this sample of incarcerated women has provided useful informaton for program planning. The analysis of existing data showed interesting results and further study to determine other relationships between other recorded data might also prove beneficial to document funding needs for program planning. Replication of this study with male offenders may facilitate further depth of understanding of lifestyle perceptions that facilitate or hinder successful reentry after incarceration. Comparison of male and female offenders perceptions of parental acceptance and rejection may warrant specific aggregate programming needs.

\section{Competing Interests}

The authors have no competing interests with the work presented in this manuscript.

\section{Author Contributions}

Barbara Joyce: Principle investigator and manuscript.

Kerry Peterson: Research team member and manuscript.

Valerie Sievers: Research team member and manuscript.

Vicki Brownrigg: Research team member and data analysis.

Vanessa Hoener: Research team member and data collection.

\section{Acknowledgements}

The authors acknowledge ComCor, Inc. of Colorado Springs for the support for the successful execution and completion of this project.

\section{References}

1. Pew Center on the States (2009) The long reach of American corrections Washington, DC: The Pew Charitable Trusts.

2. Glaze LE, Bonczar, TP (2008) Probation and parole in the United States 2007 Statistical Tables. Washington DC: Bureau of Justice Statistics, Office of Justice Programs, US Department of Justice.

3. Hanser, RD (2009) Community Corrections. Thousand Oaks, CA: Sage.

4. Bureau of Justice Statistics (1999). Women Offenders. BJS: December.

5. International Center for Prison Studies (2015).

6. Glaze LE, Bonzar TP (2011) Probation and parole in the United States 2010 Statistical Tables. Washington DC: Bureau of Justice Statistics.

7. Greenfield LA, Snell TL(1999) Women offenders. Published December 1999, Bureau of Justice Statistics, US Department of Justice.

8. Glaze L, Maruschak L (2008) Parents in prison and their minor children. Washington DC: Bureau of Justice Statistics.

9. Johnson DM (2009) Enduring violence in the lives of formerly incarcerated women: A study in individual survival and societal difference. Criminal Justice Periodicals.

10. Bond L, Semaan S (1996) At risk for HIV infection: incarcerated women in a county jail in Philadelphia. Women Health 24: 27-45.

11. Harris RM, Sharps PW, Allen K, Anderson EH, Soeken K, et al. (2003) The interrelationship between violence, HIVIAIDS, and drug use in incarcerated women. J Assoc Nurses AIDS Care 14: 27-40.

12. Krug EG, Dahlberg LL, Mercy JA, Zwi AB (2002) World report on violence and health. Lancet 360: 1083-1088.

13. Braithwaite RL, Arriola KJ, Newkirk C (2006) Health issues among incarcerated women. New Brunswick, New Jersey: Rutgers University Press.

14. Fickenscher A, Lapidus J, Silk-Walker P, Becker T (2001) Women behind bars: health needs of inmates in a county jail. Public Health Rep 116: 191196.

15. Zlotnick C (1997) Posttraumatic stress disorder (PTSD), PTSD comorbidity and childhood abuse among incarcerated women. J Nerv Ment Dis 185: 761-763
16. Harlow C (1999) Prior Abuse Reported by Inmates and Probationers. Bureau of Justice Statistics, US Department of Justice.

17. Greenfeild LA, Snell TL (1999). Women Offenders, Published December 1999, Bureau of Justice Statistics, US Department of Justice.

18. Fickenscher A, Lapidus J, Silk-Walker P, Becker T (2001) Women behind bars: health needs of inmates in a county jail. Public Health Rep 116: 191196.

19. Jordan BK, Schlenger WE, Fairbank JA, Caddell JM (1996) Prevalence of psychiatric disorders among incarcerated women: Convicted felons entering prison. Arch Gen Psychiatry 53: 513-519.

20. Maruschak L, Beck A (2001) Medical problems of inmates. Washington, DC: U.S. Department of Justice, Office of Justice Programs, Bureau of Justice Statistics.

21. Zlotnick C (1997) Posttraumatic stress disorder (PTSD), PTSD comorbidity, and childhood abuse among incarcerated women. J Nerv Ment Dis 185: 761-763.

22. James D, Glaze $L$ (2006) Mental health problems of prison and jail inmates. Washington, D.C.: Bureau of Justice Statistics.

23. Maruschak L (2008) Medical problems of prisoners. Washington, D.C.: Bureau of Justice Statistics.

24. Krug EG, Dahlberg LL, Mercy JA, Zwi AB, Lazone R (2002) World report on violence and health. Geneva, Switzerland: World Health Organization.

25. Rodner, R (2000) The warmth dimension: Foundations of Parental acceptance-rejection theory. Washington DC: Library of Congress.

26. Rodner EC, Rodner RR (1975) They love me, they love me not: A worldwide study of the effects of parental acceptance and rejection. New Haven, CT: Human Relations Area Files. 52p.

27. Kagan J (1978) The parental love trap. Psychology Today 12: 54-61.

28. Rodner RP (2005) Acceptance and rejection extended bibliography.

29. Rodner RP, Khaleque A (2005) Handbook for the study of parental acceptance and rejection. 4th edn. Storrs, CT: Rohner Research Publications.

30. Rodner RP, Khaleque A (2005) Handbook for the study of parental acceptance and rejection. 4th edn. Storrs, CT: Rohner Research Publications.

31. Elkon A (2005) Developmental correlates of antisocial behavior among incarcerated women: A retrospective study. Dissertation Abstracts International, 66, 561 .

32. Joo B (2009) The relationship between past experiences of child abuse and current parenting practices among incarcerated women. Dissertation Abstracts International, 69, 5781.

33. Esquivel ML (2010) Measurement of parental acceptance-rejection among adolescent sex offenders and non-offending siblings. Dissertation Abstracts International, 70, 4481

34. Rafail E, Haque A (1999) Relationships between perceived parental acceptance-rejection and juvenile delinquency scores: A study of criminal and non-criminal adolescents. Pakistan Journal of Psychological Research 4: 9-16.

35. Felitti VJ, Anda RF, Nordenberg D, Williamson DF, Spitz AM, et al. (1998) Relationship of childhood abuse and household dysfunction to many of the leading causes of death in adults. The Adverse Childhood Experiences (ACE) Study. Am J Prev Med 14: 245-258.

36. Corso PS, Edwards VJ, Fang X, Mercy JA (2008) Health-related quality of life among adults who experienced maltreatment during childhood. Am J Public Health 98: 1094-1100.

37. Chapman DP, Dube SR, Anda RF (2007) Adverse childhood events as risk factors for negative mental health outcomes. Psychiatric Annals 37: 359 364.

38. Rodner RP, Khaleque A (2005) Handbook for the study of parental acceptance and rejection. 4th ed. Storrs, CT: Rohner Research Publications.

39. Hairston CR (2001) Prisoners and families: parenting issues during incarceration. The Urban Institute 1-17.

40. Loucks N (2004) Prison without bars: needs, support, and good practice for work with prisoners' families. Statutory Organizations 1-98. 
Citation: Joyce B, Peterson K, Sievers V, Brownrigg V, Hoener V (2015) Relationship Between Parental Acceptance and Rejection, Documented Health Status, and Life Time Experiences of Violence Among Incarcerated Women. Int J Nurs Clin Pract 2: 147. doi: http://dx.doi.org/10.15344/2394-4978/2015/147

41. U.S. Department of Health and Human Services, Administration for Children and Families, Administration on Children, Youth and Families, Children's Bureau. Child Maltreatment 2012 [online]. Washington, DC: Government Printing Office; 2012. Poister Tusher C, Cook SL (2010) Comparing revictimization in two groups of marginalized women. J Interpers Violence 25: 1893-1911.

42. Colorado Division of Criminal Justice (2005) Standardized Offender Assessment Revised: Colorado Training Manual. Denver: State of Colorado.

43. Millon T (1982) The Millon clinical multiaxial inventory manual. Minneapolis: National Computer Systems. Rodner RP, Khaleque A (2005) Handbook for the study of parental acceptance and rejection. 4th ed. Storrs, CT: Rohner Research Publications.

44. Rodner RP, Khaleque A (2005) Handbook for the study of parental acceptance and rejection. 4th ed. Storrs, CT: Rohner Research Publications, 43p.

45. Chen X, Rubin KH (1994) Family conditions, parental acceptance and social competence and aggression in Chinese children. Social Development 3: 269-290.

46. Felner RD, Brand S, DuBois DL, Adan AM, Mulhall PF, et al. (1995) Socioeconomic disadvantage, proximal environmental experiences, and socioemotional and academic adjustment in early adolescence: investigation of a mediated effects model. Child Dev 66: 774-792.

47. Rodner RP, Khaleque A (2005) Handbook for the study of parental acceptance and rejection. 4th ed. Storrs, CT: Rohner Research Publications.

48. SPSS Inc (1999) SPSS Base Applications Guide. Chicago, III: SPSS Inc. 